\title{
DISCIPLINA CON
AMOR
}

Rubén Montero Guerrero, Mg. Facultad de Teología Universidad Peruana Unión rubenm32@yahoo.com

El rol de los padr es como educadores es fundamental en la formación de los hijos, y en esta desafiante tarea, aplicar la disciplina correctamente puede hacer la diferencia entre una buena y una mala educación. La disciplina con amor se muestra como la mejor alternativa para los padres que realmente quieren formar hijos que logren internalizar los principios y $v$ alores morales que harán de ellos personas de bien para la sociedad terrena y ciudadanos del reino de los cielos.

Palabras clave: Educación, familia, padres e hijos, disciplina, amor, carácter, confianza propia, firmeza, respeto. 
Enseñad a vuestros hijos desde la cuna a practicar la abnegación y el dominio propio... Enseñadles que ceder a la tentación es débil y perverso; que resistir es noble y viril.

Elena de White, 1913

\section{Introducción}

La disciplina puede ser entendida de diferentes maneras. A título de ejemplo, María Mújica menciona nueve usos diferentes que Agustín de Hipona hace del término disciplina. ${ }^{1}$ En términos generales, disciplina puede ser entendida como una cualidad del carácter, como alguna materia o curso a estudiar o como cas tigo que se aplica a alguien que está 80 bajo la tutoría de otra persona. El propio Agustín de Hipona usa disciplina en esta última acepción, sobre todo cuando analiza la disciplina en base a textos de la Biblia. ${ }^{2}$

La palabra disciplina tiene el mismo origen e timológico que la palabra discipulo y se refiere

$1 \quad$ En realidad ella agrupa estos nueve usos en dos grandes divisiones: una referida a la educación intelectual y otra en relación con la educación moral o la educación en general. María Lilián Mújica Rivas, "La dimensión pedagógica del término disciplina en San Agustín", Revista Española de Pedagogía 63, №. 231 (2005): 309-323.

2 Ibíd., 319-20. a la disposición q ue tienen los pupilos para seguir las normas y las reglas de com portamiento en el proceso del aprendizaje. La disciplina por tanto, aun en su etimología, está relacionada con la educación.

En este artículo entenderemos la disciplina como el entr enamiento adecuado para lograr el autocontrol, es decir, el proceso mediante el cual se ayuda al niño a incor porar los valor es y principios de vida de $t$ al manera que pueda obrar conf orme a ellos aun en la ausencia de sus padres.

\section{La necesidad de sentirse amado}

Recuerdo aquel día cuando acompañé a mi padr e a comprar en uno de los mer cados de Chimbote, la ciudad donde mi padre era el pas tor de la iglesia adventista y donde vivimos por cuatro años. Ir al viejo y bullicioso mercado todos los domingos era una costumbre que mi padre había implantado en la familia. Aquel día me $t$ ocaba acompañarlo y yo estaba feliz. Me sentía especialmente orgulloso de caminar junto a mi padre. Con frecuencia nos encontrábamos 
con hermanos de la iglesia q ue también estaban comprando.

Me gustaba ver cómo las personas lo saludaban con cariño y respeto: "Pastor, buenos días". Mientras caminábamos de un extremo al otro del mercado, pensaba "mi papi es especial, es conocido, todos lo saludan". Nuestras canastas se hacían cada vez más pesadas porque se iban llenando, entonces mi padr e apiló las canastas y bolsas en un rincón y me dijo que me quedara a cuidarlas mientras él seguía comprando y que regresaría "al toque”. Me quedé esperando y esperando, sin hacer nada más que esperar. El tiempo se hacía interminable. Las personas iban de un lugar a o tro totalmente ajenas a mi presencia. Mi padre demoraba y empecé a perder el aplomo. Me sentía inf initamente solitario y abandonado. Varias veces levanté la cabeza para divisar la silue ta de mi padr e. Cuando las lágrimas ya eran inevitables, apareció mi papá. Lo vi y salí corriendo a su encuentro.

Me recuerdo abriendo los brazos y corriendo hacia él. Me preguntó: "QQué te pasa? ¿Alguien te ha pegado?" "N o", respondí. No había absolutamente ninguna razón para estar llorando. No me preguntó nada más, tomó las bolsas y nos dispusimos a regresar a casa. Cuando recuerdo ese incidente, entiendo que no era el miedo ni la dem ora lo que me hizo llorar aquel domingo chimbotano. Ahora entiendo que lo que en realidad estaba buscando era el abrazo protector y amor oso de mi padre. Como todos los niños, y o también tenía la abrumadora necesidad de sentirme amado.

La necesidad de sentir se amados la com partimos todos los seres humanos. Es de vit al importancia que los padr es sean los primeros en satisfacer esa necesidad en la vida de sus hijos. Los hijos necesit an sentirse amados, y la mayor demostración de amor que los padres pueden dar es la pr eocupación activa por una educación int egral.

En el ámbito familiar, los padres son los llamados a educar a sus hijos y esto supone un gran desafío e im plica el cultivo de grandes dosis de paciencia y sabiduría. Dentro de los múltiples aspectos que se deben tener en cuenta en la educación de los hijos, uno de los más importan- 
tes es el relativo a la aplicación de la disciplina.

En realidad, cuando la disciplina es correctamente ejercida, en un contexto de amor pater no, trae grandes beneficios en la formación moral y espiritual de los hijos. Elena de White escribió:

Los niños serán más felices, mucho más felices, bajo la debida disciplina que si se los deja obrar siguiendo la sugerencia de sus impulsos no educados. ${ }^{3}$

Para la mayoría de los padres está claro que la aplicación de la disciplina es también una manifestación de amor, el problema es que frecuentemente eso no está claro en la per cepción de sus hijos. Es decir, muchos hijos no se sienten amados por sus padres por la manera cómo ellos los han disciplinado. El pr oblema no está en si se debe o no se debe disciplinar, es evidente que el niño necesita ser disciplinado; el problema está en la manera cómo se está disciplinando.

La disciplina con amor es aquella donde el hijo entiende

3 Elena G. de White, Conducción del Niño (Buenos Aires: Asociación Casa Editora Sudamericana, 1974), 73. que sus padres lo aman profundamente a pesar del eventual castigo que tenga que enfrentar. En la Biblia, $t$ ambién se pr esenta a la disciplina como una manifestación de amor. El sabio Salomón escribió: "P orque el SEÑOR disciplina a los q ue ama, como corrige un padr e a su hijo querido" $\left(\operatorname{Pr} 3: 12^{4}\right)$. Concluimos entonces que la verdadera disciplina en modo alguno es incompatible con el amor. Se verán a continuación, algunos rasgos sobresalientes de este tipo de disciplina.

\section{La disciplina con amor no olvida el objetivo}

Los padres que aplican eficazmente la disciplina en un contexto de amor nunca olvidan el propósito fundamental de la disciplina. Estos padres entienden que la aplicación de algún cas tigo o reprensión tiene el propósito de capacitar a su hijo para enfrentar los deberes de la vida de una manera responsable. Es decir, no se limitan a verificar que sus órdenes sean cumplidas o a querer que sus hijos se some tan continuamente a sus dictados.

$4 \quad$ Nueva Versión Internacional (Miami: Sociedad Bíblica Internacional, 1999). 
Los padres que aplican la disciplina con amor tienen una visión mucho más am plia de su tarea, ellos saben que su misión incluye preparar hombres y mujeres que sean dueños de su destino, con valores morales elevados, útiles para la sociedad y responsables de sus deberes para con Dios. Este tipo de padres comprenden que más allá de las tareas de la vida co tidiana está la preparación para esta vida y para la eternidad. 5

\section{La disciplina con amor toma en cuenta la edad y las circunstancias}

Hay padres que se jactan porque a todos sus hijos los educan igual. Es un tremendo error educar a todos los hijos por igual.

5 Elena G. de White escribió: "La madre, al contemplar al hijo que ha sido entregado a su cuidado, bien podría preguntarse con profunda ansiedad: ¿Cuál es el gran blanco y objetivo de su educación? ¿Consiste en capacitarlo para la vida y sus deberes, en calificarlo para ocupar una posición honrosa en el mundo, para hacer el bien, para beneficiar a sus semejantes, y para ganar alguna vez la recompensa de los justos? si es así, entonces la primera lección que debe enseñársele es la del dominio propio; porque ninguna persona indisciplinada y testaruda puede esperar tener éxito en este mundo o recompensa en el venidero”. Ibíd., 83.
Ejercer la disciplina con amor es tomar en cuenta las diferencias de cada uno de los hijos. Ha y diferencias de género, de edad, de temperamento, de gustos e inclinaciones, etc. En la aplicación de la disciplina es necesario tener en cuenta estas diferencias y no aplicar una educación estandarizada para personalidades diferentes. Para decirlo de o tra manera, la disciplina debe ser administrada de un modo per sonalizado, tomando en cuenta las diferencias de los hijos.

Un niño de cuatro años debe ser corregido y amones tado cuando sea necesario, per o no se le puede disciplinar como si

fuese un niño de diez años. Una niña debe recibir una disciplina diferente de la de su hermano. Para algunos niños es suficiente con hablar una v ez. Otros, por su temperamento, necesitan escuchar varias veces el mensaje.

Lo que funcione como castigo y amonestación en un hijo puede que no funcione con la misma eficacia en el o tro. Los padres sabios es tán al tanto de las diferencias entre sus hijos por más sutiles q ue éstas sean, y toman en cuenta esas diferencias al moment o de aplicar la disciplina. 


\section{La disciplina con amor es realista en sus expectativas}

Este es un aspecto importante que los padr es deben tener en cuenta para disciplinar con amor. Hay que ser realistas con las expectativas que tenemos de nuestros hijos. Es necesario analizar si las ór denes impartidas están siendo apropiadas para la edad y el nivel de madurez de los hijos. $\mathrm{No}$ se puede esperar que un niño pequeño ayude a llevar los platos de porcelana sin correr el grave riesgo de que los platos se quiebren. No es realista pedirle a un niño peq ueño que corte el césped sin ningún tipo de ayuda.

Es necesario un mínimo de sentido común para saber q ué tipo de órdenes pueden cumplir los hijos. El problema de las expectativas irreales se agrava cuando se aplica un cas tigo porque el niño no fue capaz de r ealizar algo que estaba flagrantemente por encima de sus capacidades. En realidad quienes deberían asumir toda la r esponsabilidad en estos casos son los pr opios padres.

Lo más gra ve de no cuidar este aspecto, es que cuando un niño es frecuentemente amonestado por no poder cumplir órdenes que son el producto de las expectativas exageradas de sus padres, empieza a sentir que no puede hacer bien las cosas con el consiguiente daño a su estima propia.

\section{La disciplina con amor empieza con el nacimien- to del niño}

Es posible que para algunos padres no resulte claro el momento cuando deben empezar a disciplinar a su hijo. En $r$ ealidad la aplicación de la disciplina empieza desde el momento del nacimiento. De manera paulatina los padres pueden ir creando horarios y momentos especiales para su hijo.

El horario del culto puede ser una magnífica oportunidad para que los padr es acostumbren a sus hijos a tener un tiem po de comunión con Dios. La hora de los alimentos también puede ser enseñada paulatinamente hasta crear hábitos consistentes en la vida de los niños. Esas pequeñas victorias en hábit os y cos tumbres les a yudarán a formar un carácter. Elena G. de White escribió: 
Padres, debéis principiar vuestra primera lección de disciplina cuando vuestros hijos son aún niños mamantes en vuestros brazos. $^{6}$

\section{La disciplina con amor desarrolla la confianza propia}

Uno de los efectos más perniciosos de una disciplina mal aplicada es la destrucción de la confianza propia del niño. Cuando pensamos en adultos con poca confianza en sí mismos, olvidamos que ellos fuer on niños, y que gran parte de los problemas de autoestima se remontan a la infancia que estas personas tuvieron.

Es durante la infancia que se echan las bases de lo que será la persona adulta, y es muy difícil que esta persona adulta pueda cambiar el rumbo q ue le fue marcado en su inf ancia. Recordemos que la infancia es la época en que nuestra mente recibe más intensamente la inf luencia de lo que nos rodea. En ese sentido, los padres son grandes protagonistas en la construcción de la confianza propia en un individuo. Elena de White escribió:

6 Ibíd., 214.
Es posible disciplinar a un niño para que, como la bes tia, no posea voluntad propia, al hundirse su individualidad en la de su maestro. Esta enseñanza no es buena y tiene efectos desastrosos. Los niños que son educados en esta forma carecerán de firmeza y decisión. No se los enseña a obrar por principio; las facultades del razonamiento no se fortalecen por el ejercicio. Hasta donde sea posible, cada niño debería ser enseñado a confiar en sí mismo. Al poner en ejercicio las diferentes facultades, aprenderá dónde es más fuerte y en qué es deficiente. Un instructor sabio dará atención especial al desarrollo de los $r$ asgos más débiles, a fin de que el niño forme un carácter bien equilibrado y armonioso. ${ }^{\text {? }}$

Si los padres aplican una disciplina con amor, que no destruya la voluntad del niño, es tán colaborando decisivamente en formar un adulto con una adecuada visión de sí mismo.

\section{La disciplina con amor implica explicar anticipadamente}

Uno de los errores más frecuentes de los padr es a la hora

7 Ibíd., 38. 
de disciplinar es no haber explicado con anticipación lo que espera de su hijo. Durante t odas las etapas del desarrollo, los niños deben saber con anticipación qué se espera de ellos. Los niños no son adult os en miniatura, no esper emos que ellos puedan adivinar lo q ue deben hacer.

Los padres deben decir en forma clara y sencilla el comportamiento que esperan de sus hijos, y deben asegurarse que ellos entendieron el mensaje. Es importante mantener un cont acto visual con el niño cuando se le explica lo que él debe hacer. Si es posible, hay que ponerse a la altura de los ojos del niño y $x p l i-$ carle cuáles son sus expectativas como padre. También es necesario explicar las consecuencias que su hijo tendrá que enfrentar en caso de que no cumpla con los requerimientos del padre.

En caso de q ue se ha ya explicado claramente y el padr e tiene suficientes indicios de que el niño ha comprendido, es necesario que se cumpla con la sanción acordada. No cumplir con las sanciones es una puer ta abierta a la anarquía infantil. Eso sí, hay que recordar que las sanciones tienen q ue ser pr oporcionales a la infracción y no apenas el producto del estado de ánimo del padre.

\section{La disciplina con amor se aplica con firmeza y respe- to}

La disciplina, como una $v$ erdadera manifestación de amor, debe ser aplicada con $f$ irmeza y con respeto. La firmeza no significa una dosis ma yor de severidad, en r ealidad la debemos entender como una $r$ eiterada consistencia entre las normas previamente dadas por los padres y su estricto cumplimiento.

El beneficio inmediato de una actitud de firmeza es la confianza del hijo en las palabras de su padre, y la tranq uilidad de saber que la conducta del padre es predecible en relación con las conductas de sus hijos. Esto es de gran im portancia en la af irmación de la per sonalidad de los niños.

Por otro lado, son muc hos los padres que no manif iestan el menor $r$ espeto por sus hijos al momento de disciplinar. El respeto se demues tra en las palabras que son pronunciadas al 
momento de disciplinar, y también en el cuidado para no hacer una exhibición pública que avergüence al niño. El principio bíblico se expresa en las siguientes palabras: "Padres, no irritéis a vuestros hijos para que no se desalienten".8

\section{La disciplina con amor no es consecuencia del des- control emocional}

El descontrol emocional de los padres es el context o más desfavorable para aplicar la necesaria disciplina en los hijos. Recordemos que el obje tivo de la disciplina es lograr el aut ocontrol, el gobierno de sí mismo en base a principios. $U \mathrm{n}$ padre completamente dominado por sus emociones y q ue descarga toda su ira mientras cas tiga a su hijo es un pobre ejemplo de autocontrol y gobierno de sí mismo. Elena G. de Whit e declaró lo siguiente:

Los niños son sensibles a la menor injusticia y algunos se desalientan ante ella, y no pr estarán atención a la roz de mando alta y

8 Versión Reina-Valera Actualizada (El Paso, TX: Mundo Hispano, 1989). Col 3:21. En adelante, RVA. airada, ni a las amenazas de castigo. La rebelión anida con demasiada frecuencia en el corazón de los hijos por la mala disciplina de los padres, cuando una conducta apropiada los habría inducido a adquirir un carácter bueno y ar. monioso. Una madre que no tiene perfecto dominio de sí misma no es idónea par a el manejo de sus hijos. ${ }^{9}$

Al aplicar la disciplina, el padre o la madre deben estar en perfecto control de sus emociones. Si fuese necesario, harían bien en esperar hasta obtener suficiente perspectiva y dominio de tal manera que la disciplina cumpla con el pr opósito de lograr que su hijo alcance el $t$ an ansiado control emocional.

\section{Conclusión}

La educación de los hijos nunca fue una $t$ area fácil. Hay muchas dificultades que los padres tienen que enfrentar, y una de ellas es la adminis tración de una debida disciplina. La aplicación de una corr ecta disciplina ayudará para que el niño se convierta en un adulto responsable,

9 Elena G. de White, Joyas de los Testimonios (Asociación Casa Editora Sudamericana, 1970) 1:338. 
que actúe en base a principios y normas morales elevadas.

Si seguimos los principios de la disciplina con amor, tendremos mejores posibilidades de éxito en la delicada $t$ area de la educación de nuestros hijos.

Antes de buscar el cambio en nuestros hijos, debemos cam- biar nosotros mismos. Si algún padre siente que está lejos de tener sabiduría para guiar a sus hijos, puede tener en cuenta la consoladora promesa bíblica: "Y si a alguno de vosotros le falta sabiduría, pídala a Dios, quien da a todos con liberalidad y sin $\mathrm{re}$ prochar; y le será dada" (Stg 1:5 RVA). 